\title{
Spirituality and end-of-life care in disadvantaged men dying of prostate cancer
}

\author{
Jonathan Bergman • Arlene Fink • Lorna Kwan • \\ Sally Maliski $\cdot$ Mark S. Litwin
}

Received: 27 September 2010/ Accepted: 20 October 2010/Published online: 19 December 2010

(c) The Author(s) 2010. This article is published with open access at Springerlink.com

\begin{abstract}
Purpose Despite the positive influence of spiritual coping on the acceptance of a cancer diagnosis, higher spirituality is associated with receipt of more high intensity care at the end of life. The purpose of our study was to assess the association between spirituality and type of end-of-life care received by disadvantaged men with prostate cancer.

Methods We studied low-income, uninsured men in IMPACT, a state-funded public assistance program, who had died since its inception in 2001. Of the 60 men who died, we included the 35 who completed a spirituality questionnaire at program enrollment. We abstracted sociodemographic and clinical information as well as treatment within IMPACT, including zolendroic acid, chemotherapy, hospice use, and palliative radiation therapy. We measured spirituality with the Functional Assessment of Chronic Illness Therapy-Spiritual Well-Being questionnaire
\end{abstract}

J. Bergman $(\bowtie) \cdot$ M. S. Litwin

Departments of Urology, UCLA, 951738,

Los Angeles, CA 90095-1738, USA

e-mail: jbergman@mednet.ucla.edu

A. Fink - M. S. Litwin

Departments of Health Services,

University of California, Los Angeles, CA, USA

A. Fink

Departments of Medicine, University of California,

Los Angeles, CA, USA

L. Kwan · M. S. Litwin

Jonsson Comprehensive Cancer Center,

University of California, Los Angeles, CA, USA

S. Maliski

School of Nursing, University of California,

Los Angeles, CA, USA
(FACIT-Sp) and compared end-of-life care received between subjects with low and high FACIT-Sp scores using chi-squared analyses.

Results A higher proportion of men with high (33\%) versus low (13\%) spirituality scores enrolled in hospice, although our analysis was not adequately powered to demonstrate statistical significance. Likewise, we saw a trend toward increased receipt of palliative radiation among those with higher spirituality ( $37 \%$ vs. $25 \%, P=0.69$ ). The differences in end-of-life care received among those with low and high spirituality varied little by the FACIT-Sp peace and faith subscales.

Conclusions End-of-life care was similar between men with lower and higher spirituality. Men with higher spirituality trended toward greater hospice use, suggesting that they redirected the focus of their care from curative to palliative goals.

Keywords Palliative care $\cdot$ Terminal care $\cdot$ Prostatic neoplasms $\cdot$ Utilization $\cdot$ Hospice care

\section{Introduction}

Religion and spirituality are important coping resources for many individuals with cancer, and approximately $90 \%$ of individuals dying of cancer cope with their disease under the aegis of spirituality. Most cancer survivors report higher levels of spirituality after receiving a cancer diagnosis [1-3]. Spiritual insights help those with cancer cope with their disease, positively evaluate their life, and confront possible death [4]. Spirituality uniquely contributes to the health-related quality of life of men with prostate cancer and other malignancies by allowing men to enjoy life, even when facing bothersome symptoms [5-6]. 
Spiritual beliefs also influence individuals' decisions regarding medical care, specially at the end of life [7-8]. Despite the positive influence of spiritual coping on the acceptance of a cancer diagnosis, higher spirituality is associated with use of less end-of-life planning and more high intensity care, including mechanical ventilation, cardiopulmonary resuscitation, and hospitalization at the end of life [9]. In part due to higher spirituality and a lack of advanced care planning, minorities and economically disadvantaged men utilize advanced directives a lower rate than their pecunious counterparts [10-11].

High-intensity terminal care improves neither the quantity nor the quality of life at the end of life, but it does significantly affect costs as death approaches [12-15]. The purpose of our study was to assess the association between spirituality and type of end-of-life care received by disadvantaged men with prostate cancer and to compare their care with previous descriptions of care received by more advantaged men. Based on previous studies showing increased use of high-intensity care among highly spiritual men [9], we hypothesized a priori that men with higher spirituality would utilize hospice resources less frequently than those with low spirituality, and that those with higher spirituality would be at least as likely to receive chemotherapy, palliative radiation, or zolendroic acid at the end of life. Due to previously described sociodemographic variations in hospice use $[11,14,16]$, we also posited that hospice utilization would be lower in our cohort than among men with greater economic resources.

\section{Methods}

\section{Subjects}

We studied all 35 low-income, uninsured men in a statefunded public assistance program who had died since 2001 and had completed a spirituality questionnaire at program enrollment. IMPACT-Improving Access, Counseling, and Treatment for Californians with Prostate Cancer (http:// www.california-impact.org)—was developed to provide access to prostate cancer care for uninsured men with incomes under $200 \%$ of the Federal Poverty Level [17]. Financially eligible men with biopsy-proven prostate cancer were assigned a primary cancer care provider, a clinical care coordinator, and a nurse case manager. They were also connected with counseling services, educational materials, transportation assistance, food security, and housing referrals. They were offered chemotherapy, palliative radiation therapy, zolendroic acid, or hospice care when deemed appropriate by their clinical providers. Patients with all tumor grades, disease stages, and history of previous treatment were included. IMPACT Program details have been presented previously [17-18].

All demographic and clinical information was obtained at enrollment and updated during treatment. This included age, ethnicity, job status, partnership status, region of residence (northern vs. southern California), comorbid conditions, and prior treatments.

\section{Data collection}

The University of California, Los Angeles Office for Protection of Research Subjects approved the data collection protocol, and all procedures were compliant with the Health Insurance Portability and Accountability Act. Data were abstracted from an administrative database, which included entries from case managers, care coordinators, and nursing providers. Medical chart abstraction from the IMPACT electronic clinical database and scanned paper records included review of biopsy reports, physicians' documentation of initial and follow-up visits, operative reports, consultation reports, and follow-up encounter forms. The clinical database and nurses' records were cross checked to ascertain ethnicity, income, and other demographic data. We abstracted patient enrollment in hospice; date of IMPACT enrollment; length of hospice enrollment prior to death; tumor grade; clinical disease stage at initial presentation; initial treatment received at IMPACT; subsequent treatment within IMPACT, including zolendroic acid, chemotherapy, and palliative radiation therapy; prostate-specific antigen (PSA) level prior to initial prostate cancer treatment; documented PSA closest to the time of death; metastasis at first presentation to IMPACT; date of death; and cause of death. We also noted the number of prostate cancer-related emergency room visits made while enrolled in IMPACT.

\section{Spirituality assessment}

We measured spirituality and religiosity with the Functional Assessment of Chronic Illness Therapy—Spiritual Well-Being questionnaire (FACIT-Sp) [19], which is derived from the Functional Assessment of Cancer Therapy-General survey [20]. The FACIT-Sp contains 12 unique questions, with summary scores ranging from 0 to 48; higher scores indicate greater spirituality. It contains two subscales: the peace subscale, ranging from 0 to 32 , assesses the existential impact of spirituality, while the faith subscale, ranging from 0 to 16 , measures the strength and comfort derived from faith and religious beliefs (religiosity). The FACIT-Sp has been validated across several cultures and literacy levels and has excellent reliability (Cronbach's $\alpha=0.87$ ) [6, 21]. 
Statistical analysis

Due to the right-skewed distribution of FACIT-Sp scores, we empirically dichotomized spirituality and the two subscales into low (FACEIT-Sp <27) versus high (FACIT$\mathrm{Sp} \geq 27$ ), with low spirituality defined as the lowest quartile. Similarly, we defined low (subscale score $<18$ ) and high (subscale score $\geq 18$ ) peace and low (subscale score $<8$ ) and high (subscale score $\geq 8$ ) faith. Descriptive statistics for demographic and clinical data, comparing subjects with low or high spirituality, were derived using chi-square analyses for categorical variables and the twotailed $t$ test for continuous variables. We also compared the distribution of low and high FACIT-Sp and its two subscales within each type of end-of-life care received. Statistical analyses were performed with SAS 9.2 software (SAS Institute, Cary, NC).

\section{Results}

Complete demographic and clinical data were available for all 35 subjects at enrollment. Table 1 shows the demographic, clinical, and utilization characteristics of our cohort. Minorities constituted the vast majority of the study sample, and most were partnered. According to the D'Amico risk stratification [22], all but four (11\%) men had high-risk disease at initial presentation. Androgen deprivation therapy was the most common treatment received within IMPACT. Over one-quarter of men enrolled in hospice, approximately one-third received palliative radiation therapy, about one-half were treated with zolendroic acid, and a majority received chemotherapy. Our cohort was divided relatively evenly among those making no prostate cancer-related emergency room visits ( $n=13,37 \%)$, those making one visit $(n=12,34 \%)$, and those making $\geq 2$ visits $(n=10,29 \%)$.

Bivariate analyses (Table 2) revealed that partnership status was significantly associated with spirituality $(P=$ 0.03 ) and ethnicity, biopsy Gleason score, and cause of death trended toward significance $(P<0.20)$. Age, region of residence, and clinical stage at initial diagnosis were not associated with spirituality.

Table 3 presents the distribution of spirituality and the subscales within each type of end-of-life care received. A higher proportion of men with high spirituality scores (33\%) than with low scores (13\%) enrolled in hospice, although our analysis was not powered to demonstrate statistical significance. Likewise, we saw a trend toward increased use of palliative radiation among those with higher spirituality (37\% vs. $25 \%, P=0.69$ ). The differences in end-of-life care received among those with low and high spirituality varied little by the peace and faith subscales.
Table 1 Demographic and clinical characteristics of the study sample $(n=35)$

\begin{tabular}{|c|c|}
\hline Characteristic & $\begin{array}{l}\text { Number of } \\
\text { patients }(\%)\end{array}$ \\
\hline \multicolumn{2}{|l|}{ Age (years \pm SD) } \\
\hline Mean age at IMPACT enrollment & $62.7 \pm 9.8$ \\
\hline Mean age at death & $64.2 \pm 9.7$ \\
\hline $\begin{array}{l}\text { Average length of IMPACT enrollment } \\
\text { at time of death (months } \pm \text { SD) }\end{array}$ & $18.4 \pm 13.4$ \\
\hline \multicolumn{2}{|l|}{ Ethnicity } \\
\hline White & $6(17.1)$ \\
\hline African American & $5(14.3)$ \\
\hline Hispanic & $24(68.6)$ \\
\hline \multicolumn{2}{|l|}{ Job status } \\
\hline Employed & $17(48.6)$ \\
\hline Unemployed & $18(51.4)$ \\
\hline \multicolumn{2}{|l|}{ Number of dependents } \\
\hline 0 & $13(37.1)$ \\
\hline$\geq 1$ & $22(62.9)$ \\
\hline \multicolumn{2}{|l|}{ Partnership status } \\
\hline In relationship & $25(71.4)$ \\
\hline Not in relationship & $10(28.6)$ \\
\hline \multicolumn{2}{|l|}{ Region of residence } \\
\hline Northern California & $11(31.4)$ \\
\hline Southern California & $24(68.6)$ \\
\hline \multicolumn{2}{|l|}{ Pre-treatment PSA (1 missing) } \\
\hline$<4$ & $3(8.8)$ \\
\hline $4-10$ & $4(11.8)$ \\
\hline$\geq 10$ & $27(79.4)$ \\
\hline \multicolumn{2}{|l|}{ Biopsy Gleason score } \\
\hline$\leq 6$ & $5(14.3)$ \\
\hline 7 & $11(31.4)$ \\
\hline$\geq 8$ & $19(54.3)$ \\
\hline \multicolumn{2}{|l|}{ Clinical stage } \\
\hline T1 (localized) & $13(37.1)$ \\
\hline T2 (localized) & $12(34.3)$ \\
\hline T3 (locoregional) & $5(14.3)$ \\
\hline T4 (metastatic) & $5(14.3)$ \\
\hline \multicolumn{2}{|l|}{ D'amico risk stratification } \\
\hline Low risk & $2(5.7)$ \\
\hline Intermediate risk & $2(5.7)$ \\
\hline High risk & $31(88.6)$ \\
\hline \multicolumn{2}{|l|}{ Treatment within IMPACT } \\
\hline Radical prostatectomy & $3(8.6)$ \\
\hline Radiation therapy & $1(2.9)$ \\
\hline $\begin{array}{l}\text { Radiation therapy }+ \text { androgen } \\
\text { deprivation therapy }\end{array}$ & $4(11.4)$ \\
\hline Androgen deprivation monotherapy & $26(74.3)$ \\
\hline Active surveillance & $1(2.9)$ \\
\hline \multicolumn{2}{|l|}{ End-of-life care received ${ }^{\mathrm{a}}$} \\
\hline Hospice & $10(28.6)$ \\
\hline
\end{tabular}


Table 1 continued

\begin{tabular}{ll}
\hline Characteristic & $\begin{array}{l}\text { Number of } \\
\text { patients }(\%)\end{array}$ \\
\hline Zolendroic acid & $16(45.7)$ \\
Chemotherapy & $22(62.9)$ \\
Palliative radiation therapy & $12(34.3)$ \\
PSA closest to date of death (1 missing) & \\
$\leq 4$ & $6(17.7)$ \\
$4-10$ & $3(8.8)$ \\
$\geq 10$ & $25(73.5)$ \\
Number of prostate cancer-related emergency room visits \\
0 & $13(37.1)$ \\
1 & $12(34.3)$ \\
$\geq 2$ & $10(28.6)$ \\
Evidence of metastases at presentation to IMPACT & \\
Cause of death & $25(71.4)$ \\
Prostate cancer & $26(74.3)$ \\
Other & $9(25.7)$ \\
\hline
\end{tabular}

$\overline{{ }^{a}}$ Types of end-of-life care were not mutually exclusive and could therefore sum more than $100 \%$

\section{Conclusions}

Our study has three important findings. First, in contrast with previous analyses and our hypothesis, we noted a trend toward higher rates of hospice utilization among more spiritual men [9]. This suggests that highly spiritual men redirected the focus of their care from curative goals to palliation and quality of life. The hospice model of patient care focuses on controlling symptoms, facilitating emotional and spiritual well-being, ensuring patient autonomy, and supporting caregivers [16]. Compared with individuals dying of cancer who do not receive hospice care, those who do have better pain control and improved quality of life at the end of life [12, 23]. Despite this, many people with metastatic cancer do not utilize hospice services [14]. One reason that individuals may not enroll in hospice is an unwillingness to forgo aggressive treatments, even at a stage when those treatments can neither cure disease nor improve quality of life. A recent prospective, multisite analysis of a longitudinal cohort of individuals with advanced cancer showed that those with higher spirituality received more high-intensity, life-prolonging care at the end of life, including mechanical ventilation or cardiopulmonary resuscitation [9]. Such aggressive, futile end-of-life care is antithetical to the hospice model, and individuals who wish to aggressively treat incurable disease are less likely to enroll in hospice [10, 13, 24]. Jacobs, et al. [8] have shown that a majority of individuals in the general public believe God can heal a patient even after medical providers agree the disease is no longer curable, which may partially explain the underuse of hospice among individuals with almost all terminal conditions [14].

That highly spiritual men within IMPACT utilized hospice at least as often as their less-spiritual counterparts suggests that spiritual beliefs did not prevent them from accepting the incurability of their prostate disease. One reason spirituality may have affected men in IMPACT differently than it influenced subjects in the Phelps study [9] is IMPACT's comprehensive cancer care model. In addition to providing prostate cancer care, IMPACT also offers generous clinical and non-clinical services targeting the extrinsic factors associated with disparities in treatment outcomes among disadvantaged men. The design of the program incorporates measures to help reduce the outcome disparities often seen in low-income and uninsured patients after prostate cancer treatment. These value-added services include counseling and interpreter services, culturally competent and literacy-sensitive educational materials in multiple languages, transportation assistance, food security and housing referrals, and nurse-managed care for all IMPACT enrollees. While spirituality typically leads to less advanced care planning and higher-intensity end-oflife care (including less-frequent hospice use), specially among minorities [10-11, 25], our findings suggest that comprehensive cancer care like that delivered within IMPACT may loosen the tether between spirituality and aggressive end-of-life care. From a policy perspective, the comprehensive care model may better serve both the individual and the health care system.

Second, among men with both low and high spirituality, the pattern of end-of-life care in our cohort was consistent with previous reports of higher-income, insured individuals, although these patterns were suboptimal in both populations. Earle, et al. [26] have identified frequent emergency room visits, continuation of anticancer therapies very near death, and a high proportion of individuals never referred to hospice or referred in the last few days of life as indicators of poor-quality, end-of-life care. Individuals enrolled in hospice for fewer than 7 days before death have insufficient time to benefit from myriad hospice resources, while hospice referrals made more than 180 days before dying are considered too early [13-14, 16]. Once terminally ill patients present to an emergency room, approximately $35 \%$ are hospitalized and die during hospital admission, while another $35 \%$ are hospitalized, aggressively treated, and discharged [24]. Frequent emergency room visits, inpatient admissions, and intensive care unit stays not only constitute poor-quality, end-of-life care but also contribute disproportionately to the cost of care [27]. In our cohort, $29 \%$ of men made two or more prostate cancer-related emergency room visits, 29\% enrolled in hospice, and none enrolled in hospice within 7 days of death. While previous studies, the majority of 
Table 2 Bivariate analysis of demographic and clinical characteristics by spirituality scores $(n=35)$

\begin{tabular}{|c|c|c|c|}
\hline \multirow[t]{2}{*}{ Characteristic } & \multicolumn{3}{|c|}{ Number of patients $(\%)$} \\
\hline & $\begin{array}{l}\text { Low } \\
\text { FACIT-Sp } \\
<27(n=8)\end{array}$ & $\begin{array}{l}\text { High } \\
\text { FACIT-Sp } \\
\geq 27(n=27)\end{array}$ & $P$ value \\
\hline \multicolumn{4}{|l|}{ Age $($ years \pm SD) } \\
\hline $\begin{array}{l}\text { Mean age at IMPACT } \\
\text { enrollment }\end{array}$ & $61 \pm 9$ & $63 \pm 10$ & 0.65 \\
\hline Mean age at death & $63 \pm 8$ & $65 \pm 10$ & 0.60 \\
\hline \multicolumn{4}{|l|}{ Ethnicity } \\
\hline White & $3(38)$ & $3(11)$ & 0.17 \\
\hline African American & $0(0)$ & $5(19)$ & \\
\hline Hispanic & $5(62)$ & $19(70)$ & \\
\hline \multicolumn{4}{|l|}{ Job status } \\
\hline Employed & $2(25)$ & $15(56)$ & 0.23 \\
\hline Unemployed & $6(75)$ & $12(44)$ & \\
\hline \multicolumn{4}{|l|}{ Number of dependents } \\
\hline 0 & $4(50)$ & $9(33)$ & 0.43 \\
\hline$\geq 1$ & $4(50)$ & $18(67)$ & \\
\hline \multicolumn{4}{|l|}{ Partnership status } \\
\hline In relationship & $3(38)$ & $22(81)$ & 0.03 \\
\hline Not in relationship & $5(62)$ & $5(19)$ & \\
\hline \multicolumn{4}{|l|}{ Region of residence } \\
\hline Northern California & $2(25)$ & $9(33)$ & 1.0 \\
\hline Southern California & $6(75)$ & $18(67)$ & \\
\hline \multicolumn{4}{|l|}{ Pre-treatment PSA } \\
\hline$\leq 4$ & $1(13)$ & $2(8)$ & 0.61 \\
\hline $4-10$ & $0(0)$ & $4(15)$ & \\
\hline$\geq 10$ & $7(87)$ & $20(77)$ & \\
\hline \multicolumn{4}{|l|}{ Biopsy Gleason score } \\
\hline$\leq 6$ & $3(38)$ & $2(7)$ & 0.06 \\
\hline 7 & $3(38)$ & $8(30)$ & \\
\hline$\geq 8$ & $2(25)$ & $17(67)$ & \\
\hline \multicolumn{4}{|l|}{ Clinical stage } \\
\hline T1 (localized) & $3(38)$ & $10(37)$ & 0.56 \\
\hline T2 (localized) & $3(38)$ & $9(33)$ & \\
\hline T3 (locoregional) & $0(0)$ & $5(19)$ & \\
\hline T4 (metastatic) & $2(25)$ & $3(11)$ & \\
\hline \multicolumn{4}{|l|}{ D'amico risk stratification } \\
\hline Low risk & $1(13)$ & $1(4)$ & 0.22 \\
\hline Intermediate risk & $1(13)$ & $1(4)$ & \\
\hline High risk & $6(75)$ & $25(93)$ & \\
\hline \multicolumn{4}{|l|}{ Treatment within IMPACT } \\
\hline Radical prostatectomy & $1(13)$ & $2(7)$ & 0.33 \\
\hline Radiation therapy & $0(0)$ & $1(4)$ & \\
\hline $\begin{array}{l}\text { Radiation therapy }+ \text { androgen } \\
\text { deprivation }\end{array}$ & $0(0)$ & $4(15)$ & \\
\hline $\begin{array}{l}\text { Androgen deprivation } \\
\text { monotherapy }\end{array}$ & $6(75)$ & $20(74)$ & \\
\hline Active surveillance & $1(13)$ & $0(0)$ & \\
\hline \multicolumn{4}{|l|}{ PSA closest to date of death } \\
\hline$\leq 4$ & $2(25)$ & $4(15)$ & 0.52 \\
\hline $4-10$ & $1(13)$ & $2(8)$ & \\
\hline$\geq 10$ & $5(63)$ & $20(77)$ & \\
\hline
\end{tabular}

Table 2 continued

\begin{tabular}{llll}
\hline Characteristic & \multicolumn{3}{l}{ Number of patients $(\%)$} \\
\cline { 2 - 4 } & $\begin{array}{l}\text { Low } \\
\text { FACIT-Sp } \\
<27(n=8)\end{array}$ & $\begin{array}{l}\text { High } \\
\text { FACIT-Sp } \\
\geq 27(n=27)\end{array}$ & $P$ value \\
\hline Number of emergency room visits & & \\
0 & $2(25)$ & $11(41)$ & 0.61 \\
1 & $4(50)$ & $8(30)$ & \\
$\geq 2$ & $2(25)$ & $8(30)$ & \\
Evidence of metastases & $5(63)$ & $20(74)$ & 0.66 \\
at presentation to IMPACT & & & \\
Cause of death & & & \\
Prostate cancer & $4(50)$ & $22(81)$ & 0.16 \\
Other & $4(50)$ & $5(19)$ & \\
\hline
\end{tabular}

which retrospectively analyzed insured, mostly white individuals, reported similar utilization trends at the end of life, our findings suggest several avenues to improve endof-life care $[14,28]$. Addressing medical problems before they turn emergent may obviate the need to spend one-third of all Medicare resources at the end of life [15]. Likewise, improving the overall rate of hospice utilization, in both underserved individuals like those in IMPACT and in more privileged populations, may help deliver higher-quality end-of-life care at lower cost.

Third, the associations we noted between spirituality and end-of-life care did not change in our subgroup analyses of the peace and faith subscales of the FACIT-Sp. Rather, the trends we noted between total FACIT-Sp scores and use of hospice, zolendroic acid, chemotherapy, and palliative radiation differed negligibly by the contribution of peace or faith to spirituality. The peace subscale of the FACIT-Sp assesses the contribution of spirituality to meaning, peace, and purpose in life, while the faith subscale measures the relationship between illness and spiritual beliefs. Some previous reports have shown that the peace subscale correlates with mental and physical health, while faith correlates with mental health exclusively, but the subscales are usually collinear $[6,21]$. Our findings suggest that both peace and faith affect men's decisions at the end of life in a similar manner. Addressing end-of-life goals and expectations with all spiritual men may help them navigate life's final chapter more knowledgeably.

Our findings are limited by several methodological considerations. First, our small sample size risks type II error, wherein we incorrectly failed to reject the null hypothesis of no difference between the low- and highspirituality groups. We lacked power to definitively demonstrate that no difference existed between men with lower and higher spirituality. As such, our analysis is hypothesisgenerating and begs for further study. Second, the vast majority of men in our cohort presented to IMPACT with 
Table 3 End-of-life care received, stratified by spirituality scores $(n=35)$

\begin{tabular}{|c|c|c|c|c|c|c|c|c|c|c|c|c|}
\hline & \multicolumn{12}{|c|}{ Number of patients (\%) } \\
\hline & \multicolumn{3}{|c|}{ Hospice } & \multicolumn{3}{|c|}{ Zolendroic acid } & \multicolumn{3}{|c|}{ Chemotherapy } & \multicolumn{3}{|c|}{ Palliative radiation } \\
\hline & Yes & No & $P$ value & Yes & No & $P$ value & Yes & No & $P$ value & Yes & No & $P$ value \\
\hline \multicolumn{13}{|l|}{ Spirituality } \\
\hline Low $(<27)$ & $1(10)$ & $7(28)$ & 0.39 & $4(25)$ & $4(21)$ & 1.0 & $5(23)$ & $3(23)$ & 1.0 & $2(17)$ & $6(26)$ & 0.69 \\
\hline High $(\geq 27)$ & $9(90)$ & $18(72)$ & & $12(75)$ & $25(79)$ & & $17(77)$ & $10(77)$ & & $10(83)$ & $17(74)$ & \\
\hline \multicolumn{13}{|c|}{ Peace subscale } \\
\hline Low $(<18)$ & $1(10)$ & $6(24)$ & 0.64 & $4(25)$ & $3(16)$ & 0.68 & $5(23)$ & $2(15)$ & 0.69 & $2(17)$ & $5(22)$ & 1.0 \\
\hline High $(\geq 18)$ & $9(90)$ & $19(76)$ & & $12(75)$ & $16(84)$ & & $17(77)$ & $11(85)$ & & $10(83)$ & $18(78)$ & \\
\hline \multicolumn{13}{|l|}{ Faith subscale } \\
\hline Low $(<8)$ & $1(10)$ & $6(24)$ & 0.64 & $4(25)$ & $3(16)$ & 0.68 & $5(23)$ & $2(15)$ & 0.69 & $2(17)$ & $5(22)$ & 1.0 \\
\hline $\operatorname{High}(\geq 8)$ & $9(90)$ & $19(76)$ & & $12(75)$ & $16(84)$ & & $17(77)$ & $11(85)$ & & $10(83)$ & $18(78)$ & \\
\hline
\end{tabular}

metastatic disease, many after having received primary prostate cancer treatment elsewhere. Whether the patterns of end-of-life care we elucidated would differ if men had been enrolled in a comprehensive cancer care program at initial diagnosis remains an open question, and indeed a distinct possibility.

Despite these limitations, the nature of the IMPACT program and our data collection methods strengthen the potential value of our conclusions. The extensive clinical and psychosocial notes entered by IMPACT providers were available for our perusal, so we needed not rely on analyses based on claims or death certificates. We were able to view all notes from medical, nursing, and ancillary providers to understand end-of-life care in our subjects more robustly than if we had used only administrative data.

We describe the associations between spirituality and patterns of end-of-life care among low-income, uninsured men with prostate cancer. End-of-life care was similar between men with lower and higher spirituality. Patterns of care in our underserved cohort were comparable with those of more affluent, insured individuals. These patterns remain poorly understood and must be rationally systemized to ensure delivery of high-quality, cost-effective, endof-life care.

\section{Conflict of interest None.}

Open Access This article is distributed under the terms of the Creative Commons Attribution Noncommercial License which permits any noncommercial use, distribution, and reproduction in any medium, provided the original author(s) and source are credited.

\section{References}

1. Silberfarb PM, Anderson KM, Rundle AC, Holland JC, Cooper MR, McIntyre OR (1991) Mood and clinical status in patients with multiple myeloma. J Clin Oncol 9:2219-2224
2. Balboni TA, Vanderwerker LC, Block SD et al (2007) Religiousness and spiritual support among advanced cancer patients and associations with end-of-life treatment preferences and quality of life. J Clin Oncol 25:555-560

3. Roberts JA, Brown D, Elkins T, Larson DB (1997) Factors influencing views of patients with gynecologic cancer about endof-life decisions. Am J Obstet Gynecol 176:166-172

4. Thomas J, Retsas A (1999) Transacting self-preservation: a grounded theory of the spiritual dimensions of people with terminal cancer. Int J Nurs Stud 36:191-201

5. Whitford HS, Olver IN, Peterson MJ (2008) Spirituality as a core domain in the assessment of quality of life in oncology. Psychooncology 17:1121-1128

6. Brady MJ, Peterman AH, Fitchett G, Mo M, Cella D (1999) A case for including spirituality in quality of life measurement in oncology. Psychooncology 8:417-428

7. Silvestri GA, Knittig S, Zoller JS, Nietert PJ (2003) Importance of faith on medical decisions regarding cancer care. J Clin Oncol 21:1379-1382

8. Jacobs LM, Burns K, Bennett Jacobs B (2008) Trauma death: views of the public and trauma professionals on death and dying from injuries. Arch Surg 143:730-735

9. Phelps AC, Maciejewski PK, Nilsson M et al (2009) Religious coping and use of intensive life-prolonging care near death in patients with advanced cancer. Jama 301:1140-1147

10. Johnson KS, Elbert-Avila KI, Tulsky JA (2005) The influence of spiritual beliefs and practices on the treatment preferences of African Americans: a review of the literature. J Am Geriatr Soc 53:711-719

11. Crawley L, Payne R, Bolden J, Payne T, Washington P, Williams $S$ (2000) Palliative and end-of-life care in the African American community. Jama 284:2518-2521

12. Berry DL, Moinpour CM, Jiang CS et al (2006) Quality of life and pain in advanced stage prostate cancer: results of a southwest oncology group randomized trial comparing docetaxel and estramustine to mitoxantrone and prednisone. J Clin Oncol 24: 2828-2835

13. Dy SM, Shugarman LR, Lorenz KA, Mularski RA, Lynn J (2008) A systematic review of satisfaction with care at the end of life. J Am Geriatr Soc 56:124-129

14. McCarthy EP, Burns RB, Ngo-Metzger Q, Davis RB, Phillips RS (2003) Hospice use among medicare managed care and fee-forservice patients dying with cancer. Jama 289:2238-2245

15. Yabroff KR, Lamont EB, Mariotto A et al (2008) Cost of care for elderly cancer patients in the United States. J Natl Cancer Inst 100:630-641 
16. Schonwetter R (2006) Hospice and palliative medicine goes mainstream. J Palliat Med 9:1240-1242

17. Maliski SL, Clerkin B, Litwin MS (2004) Describing a nurse case manager intervention to empower low-income men with prostate cancer. Oncol Nurs Forum 31:57-64

18. Miller DC, Gelberg L, Kwan L et al (2008) Racial disparities in access to care for men in a public assistance program for prostate cancer. J Community Health 33:318-335

19. Peterman AH, Fitchett G, Brady MJ, Hernandez L, Cella D (2002) Measuring spiritual well-being in people with cancer: the functional assessment of chronic illness therapy-spiritual wellbeing scale (FACIT-Sp). Ann Behav Med 24:49-58

20. Cella DF, Tulsky DS, Gray G et al (1993) The functional assessment of cancer therapy scale: development and validation of the general measure. J Clin Oncol 11:570-579

21. Canada AL, Murphy PE, Fitchett G, Peterman AH, Schover LR (2008) A 3-factor model for the FACIT-Sp. Psychooncology 17:908-916

22. D'Amico AV, Whittington R, Malkowicz SB et al (1998) Biochemical outcome after radical prostatectomy, external beam radiation therapy, or interstitial radiation therapy for clinically localized prostate cancer. Jama 280:969-974

23. Schonwetter RS, Roscoe LA, Nwosu M, Zilka B, Kim S (2006) Quality of life and symptom control in hospice patients with cancer receiving chemotherapy. J Palliat Med 9:638-645

24. Cintron A, Hamel MB, Davis RB, Burns RB, Phillips RS, McCarthy EP (2003) Hospitalization of hospice patients with cancer. J Palliat Med 6:757-768

25. Bullock K (2006) Promoting advance directives among African Americans: a faith-based model. J Palliat Med 9:183-195

26. Earle CC, Park ER, Lai B, Weeks JC, Ayanian JZ, Block S (2003) Identifying potential indicators of the quality of end-oflife cancer care from administrative data. J Clin Oncol 21:1133-1138

27. Earle CC, Neville BA, Landrum MB, Ayanian JZ, Block SD, Weeks JC (2004) Trends in the aggressiveness of cancer care near the end of life. J Clin Oncol 22:315-321

28. Virnig BA, Marshall McBean A, Kind S, Dholakia R (2002) Hospice use before death: variability across cancer diagnoses. Med Care 40:73-78 